\title{
An Analytical Validation of the National Statistics Authority Consumer Satisfaction Survey: Towards Improving Public Service Assessment Construct
}

\author{
Rosita G. Santos ${ }^{1 *}$ \\ \{rosita.santos@lpu.edu.ph $\left.{ }^{1}\right\}$ \\ ${ }^{1}$ Lyceum of the Philippines (LPU), Manila Campus, \\ Muralla St, Intramuros, Manila, 1002 Metro Manila, Philippines
}

\begin{abstract}
Consumer satisfaction research has risen in the private sector. Public sector agencies have also adopted consumer satisfaction feedback on consumer needs, values and satisfaction. The National Statistics Authority's documents registry program has equally adopted consumer surveys to determine consumer satisfaction index that guides its operations.Through a qualitative descriptive, the study validated NSA's consumer survey by analyzing survey results and validating these through ocular observation and walk-on interviews in three outlets. The study confirmed the satisfactory consumer index, but took cognizance of the NSA survey use of the single variable of queuing time improvement in methodical steps to deliver services.Proposal to improve the survey construct through more variables (technical, social, physical) was suggested for determining total consumer satisfaction. Full computerization was recommended for automation was registry services that reach out to Filipinos abroad and far-flung places in the archipelago.
\end{abstract}

Keywords: Consumer Satisfaction; Consumer Satisfaction Index; Index Variables; FullComputerization; Ocular Observation; Registry Documents; Queuing Improvement; Walk-On Interviews.

\section{Introduction}

in the private sector $[1,2]$. This is in the interest of private firms to boost up economic value and profitability through useful feedback on consumer needs, value and satisfaction of services and product [3]. The public sector including the National Statistics Authority (NSA) has rightfully used consumer satisfaction research, among which is a consumer satisfaction index on NSA's computerized registry documents delivery so vital for public needs in securing permits, for travel, employment clearance, marriage, etc. The NSA's adoption of a computerized system has certainly boosted up NSA registry operations by shortening queuing time, processing and release of registry documents namely birth, death, and marriage certificates. With the country's population growth which has today reached more than a 100 million, official registry has also increased tremendously both at the local and the national levels. To date, the NSA has six Metro Manila outlets in Quezon, Pasay, Caloocan, Makati, Muntinlupa and Pasig cities. Bulk of registry document applicants each day number into thousands, if not tens of thousands in these outlets most especially in the main NSA at East Avenue, Quezon City. Computerization has served to imbue speed, efficiency and integrity 
into NSA's registry services, as its regular monthly consumer service surveys attest to this. As the NSA functions as the central statistical authority of the Philippine government on primary data collection, analysis and administration of civil registry function,avalidation study of its consumer satisfaction feedback deserves consideration.

Research studies on consumer satisfaction have been on the rise the past decade,further accelerated by concepts accrued from the use of computer systems.Computerized operations greatly enhanced consumer satisfaction in many fields in the commercial and public sectors $[4,5]$. The advantages and disadvantages of computerized systems are considered along experiential aspects of computerized operations. Use of the system determines whether it is beneficial or detrimental to operations, while there is the opposite perspective on whether benefits outweigh losses or the other way around. Advantages identified are greater efficiency in performing specific tasks, larger storage capacity for documents and data, as well as enlivening operations [6].

Advantages in the workplace point to streamlining of operations that require less staff or employees. While there is feat that computerization can endanger job securitythere is also the resultant creation of challenging new jobs, as well as the opening of new professional fields.Among new extensions credited computerization are in civil service, drafting services, electronic accounting, information services, portfolio management services.[7]. Public registry services have benefitted from computerization in contributing to diversity in registry operations, public safety and crime records filing, care provider registry referral, etc. Data access on national health-and death is exemplified by the National Center for Health Situation and its centralized database on health and death records [8].

The call for simplified revenue generation resulted in the adoption of an effective semiautomated tax mapping system by the Quezon City Assessor's Office. The transition from a labor intensive paper-based to a semi-operated operation was realized throughdigitization of tax maps and launching of a proprietary client-server technology.A fully automated Geographic Information System (GIS) is foreseen as the nest step toinstitute enhancement of tax mapping and improve delivery of services [9, 10].

As provided for in Act No. 3753, the National Statistics Authority is assigned the function to "Carry out, enforce and administer civil registration functions in the country" [11]. It collaborates with other departments on the national government including GovernmentOwned-Corporate-Companies and Local Government units in the collection, computation, maintenance and publication of statistical information, including statistical data derived from these departments and their subsidiaries.NSA has therefore developed and maintained appropriate framework and standards for collecting, processing, analysis and dissemination of data including registry documents which are of vital interest to the general public. For the past decade, the NSA has also embarked on a computerized system particular in providing applicant-consumers who need official certificates of birth, death and marriage required for travel, employment, marriage, etc.

The main problem is to determine the validity of the NSA consumer satisfaction survey by way of analysis of survey results most recently posted online by the NSA website.The study is important for continuing efforts to give value to consumer satisfaction particularly inpublic services. Gaining consumer intelligence will certainly boost public support for government and its officialdom, while serving to respond topublic need and welfare. In particular, the study can benefit NSA by upgrading its continuing consumer satisfaction survey.Registry public consumers can benefit through services that incorporate human variable along technical, social and physical parameters.Model consumer satisfaction construct can be applied and be advantages to all agencies of government other than the 
NSA.Prospects for full computerization of NSA registry services shall benefit Filipinos all over the archipelago and abroad.

\section{Conceptual Framework}

Figure 1 illustrates the paradigm for comparison analysis of NSA consumer satisfaction on registry service to public consumers. The National Statistics Authority conducts a consumer survey in all NSA registry outlets to determine the level of consumer satisfaction of applicants who request official registry documents (birth, death and marriage).One determining variable is used and this is on queuing time that is being facilitated by a computerized system to search, retrieve and copy/print registry documents. The study conducted what can be a model consumer satisfaction survey construct by amplifying variables to include the technical, social and physical facets of consumer satisfaction, resulting in a total consumer index.Queuing time variable has also been validated by ocular visit for visible observation of actual operations in three NSA outlet sites, namely Quezon, Pasay and Caloocan cities coupled with random casualinterviews to draw the more meaningful perceptions on how NSA registry operations are satisfactory, less or not satisfactory in terms ofpublic service.

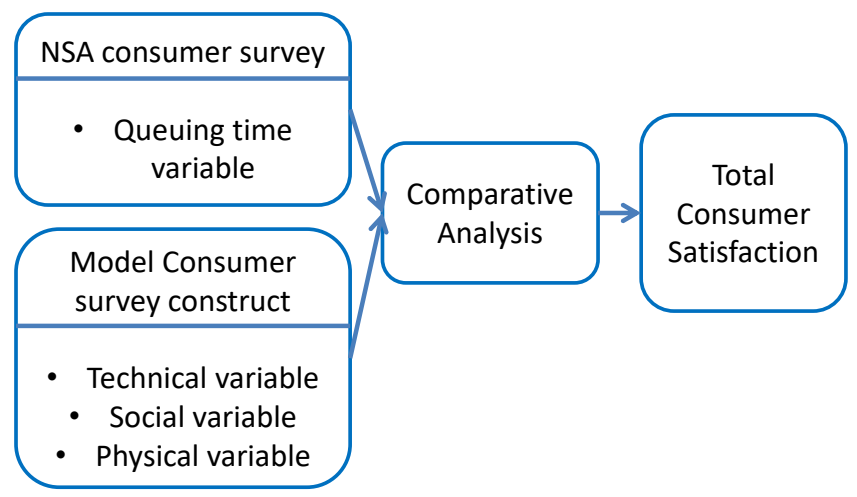

Figure 1. Paradigm for comparison analysis of NSA consumer satisfaction on registry service to public consumers

\section{Methodology}

The study utilized the descriptive method of research qualitatively and quantitatively.It analyzed data results from an official NSA survey on consumer satisfaction which retrieved from September 2016. Then, data were subsequently validated by observation of registry operations and consumer perception of registry services at three NSA outlets. This method thus described the visible situation as they existed at the time of the conducted visit-interviews with participants.

\section{Research participants}

Validation analysis through random interviews involved thirty (30 participants), ten (10) from each outlet. A common interview template with three variables (technical, social and physical) was used to arrive at a total consumer satisfaction index.Interview profile reflected 
NSA's survey profile, namely 60 percent female, two of every five or 40 percent within the 20-29 age groups. Majority or 60 percent had at lease college education. More than half of interviewed clients or 70 percent resided in Metro Manila, while only 25 percent of one-offour came from areas outside Metro Manila.

\section{Research Instrument}

While the NSA consumer satisfaction survey focused singly on the variable of queuing and the shortened time for delivery of service to clients, visit-interviews required adoption of more extensive variables to consumer satisfaction.

The technical to include methodical and efficient processing steps consisting of various steps, namely

Step 1. A application forms distribution section either for birth, death, marriage or CENOMAR or No-marriage certificate.

Step 2. Applicant filling-up of forms

Step 3. Correction checking of filled up forms by NSA first-line staff.

Step 4. Queue for submission and payment in submission and payment booths. In Caloocan, Muntinlupa and Makati city outlets, payment is received by the City Hall Cashier rather than NSA booth.

Step 5. Second queue for release of registry documents.

\section{Result And Discussion}

\section{Demographic profile of NSA survey participants}

Table 1 tabulates the distribution of NSO clients by demographic profile: December 2012. From Table 1, on participant's age, clients from ages 15-34 composed more than half of daily registry applicants. Clients from ages 35-49 compose one-fourth of applicants. Only 5.5 percent and 6.7 percent compose applicants in the 15-19 and 55-60 age groups. Next on education, those who reached college or higher education composed the majority of clients compared with only 2.9 percent and 32.3 percent of those in the elementary and high school grades respectively. Besides that, on work, there were more than half were unemployed and understandably need registry documents for employment. The employed composed a little less than half and would understandably need documents for other purposes such as travel, marriage, business, etc. Lastly is about residence, majority were from the National Capital Region, while a fourth segment were from outside the Metropolis. Data on residence do not reveal the need of those who leave more remote provinces in the northern parts of Luzon and in the Visayas and Mindanao. The need for the NSA to establish NSA outlets in these areas is apparent.

Table 1. Distribution of NSO Clients by Demographic Profile: December 2012

\begin{tabular}{|l|l|l|}
\hline Criteria & Categories & Percentage (\%) \\
\hline Gender & Male & 39.6 \\
\cline { 2 - 3 } & Female & 60.4 \\
\hline \multirow{4}{*}{ Age Group } & 15 to 19 & 5.5 \\
\cline { 2 - 3 } & 20 to 24 & 19.6 \\
\cline { 2 - 3 } & 25 to 29 & 20.9 \\
\cline { 2 - 3 } & 30 to 34 & 16.8 \\
\cline { 2 - 3 } & 35 to 39 & 9.7 \\
\cline { 2 - 3 } & 40 to 44 & 10.3 \\
\hline
\end{tabular}




\begin{tabular}{|l|l|l|}
\hline \multirow{4}{*}{ Education } & 45 to 49 & 6.6 \\
\cline { 2 - 3 } & 50 to 54 & 4.3 \\
\cline { 2 - 3 } & 55 to 59 & 3.8 \\
\cline { 2 - 3 } & 60 and above & 2.7 \\
\cline { 2 - 3 } & Elementary & 2.9 \\
\cline { 2 - 3 } & High school & 32.3 \\
\cline { 2 - 3 } Work & College or higher & 64.8 \\
\hline \multirow{3}{*}{ Residence } & Employed & 46.6 \\
\cline { 2 - 3 } & Unemployed & 53.4 \\
\cline { 2 - 3 } & NCR & 75.6 \\
\hline & Outside NCR & 24.4 \\
\hline
\end{tabular}

\section{Purposes and types of for securing registry documents}

Table 2 shows the distribution of client's purpose for requesting civil registry documents: December 2012. There are varied reasons why registry documents are needed by the public. Official documents serve to ascertain name, birthdays, death, or marriage. These documents forestall fraudulent or criminal intent among persons who apply for jobs, travel abroad and transact business or other engagements. Table 2 shows that majority or almost half of requests for registry documents are for travel, namely for getting a passport and Embassy requirements. Other needs follow namely for local employment (17.1\%). school (12.1\%) and others.

Table 2. Distribution of Clients purpose for requesting civil registry documents:

December 2012

\begin{tabular}{|l|l|}
\hline Purpose & Percentage (\%) \\
\hline Passport & 30.9 \\
\hline Embassy & 14.9 \\
\hline School & 12.1 \\
\hline Local employment & 17.1 \\
\hline GSIS/SSS & 10.1 \\
\hline BIR & 1.5 \\
\hline Baptism & 3.2 \\
\hline Exam/PRC & 2.1 \\
\hline Marriage & 4.9 \\
\hline Others & 7.5 \\
\hline
\end{tabular}

Table 3 demonstrates the distribution of type of document requested in December 2012. Most documents needed were for birth certificate which is basically needed for many travel, employment, education, etc. There is lesser demand for marriage documents consisting of marriage certificates and CENOMAR or non-marriage certificates.

Table 3. Distribution of Type of Document Requested: December 2012

\begin{tabular}{|l|l|}
\hline Type & Percentage (\%) \\
\hline Birth & 68.2 \\
\hline Marriage & 17.8 \\
\hline Death & 4.5 \\
\hline CENOMAR & 9.2 \\
\hline Prewar & 1.2 \\
\hline Authentication & 1.6 \\
\hline
\end{tabular}




\section{NSA satisfaction survey}

Figure 2 illustrates a graph shows a satisfactory net satisfaction rating (average +75.80 for 2009-2012). Single variable of reduced time for queuing was used for the NSA continuing survey. From the documentary report of the survey, a total of 642 thousand processed transactions were reported in 2012, providing estimate of consumers from year-to-year.

The East Avenue Main Outlet had the biggest proportion (70\%) or clients followed by recorded clients in Muntinlupa (36\%). Comparatively, there were more clients (84.3\%) in civil registry services in East Avenue than in other outlets.

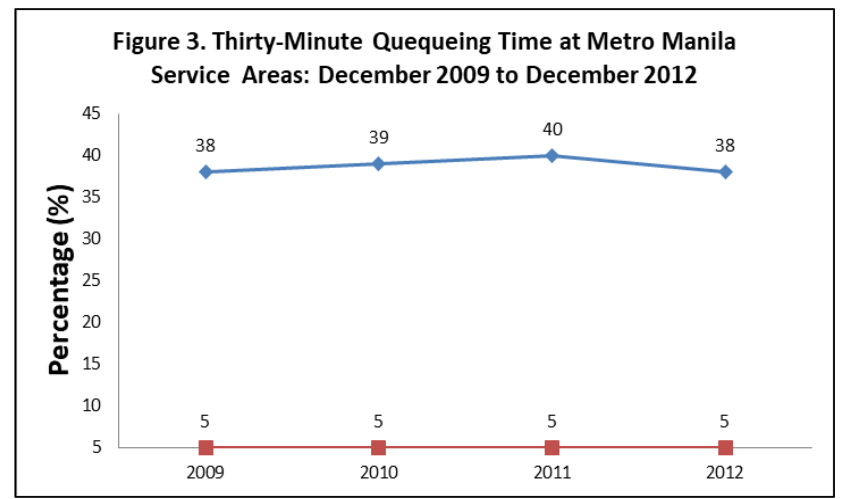

Figure 2. The consumer satisfaction survey of the NSA revealed satisfactory rating by consumers on NSA registry services.

\section{Data from Ocular Observation and Interviews}

Random interview did not differ by way of demographic profile, purpose and kinds of documents and other data from the NSA consumer satisfaction survey. However interviews provided the following observed facts and data:

On technical variable:

The process of registry document filing adopted a methodical and efficient process of steps facilitated by security personnel.

Step 1. Application forms were made available by Security and staff personnel.

Step 2. Clients fill up forms in available writing desks, and forms submitted for checking and correction by the NSA staff.Clients are advised to present required authorization papers, if needed such as by applicants not in direct line of parentage to names/persons requiring documents.Children and grandchildren are allowed to request documents for parents, and parents in turn for their children. Brothers, cousins and other persons need to present certificates of authorization to secure requested documents.

Step 3. Clients queue for submission of forms in submission booth together with payments. In NSA outlets in Caloocan, Makati and Muntinlupa, payments are made at the city cashier's office.

Step 4. Clients wait for one to two hours (depending on volume of applicants during the day)to queue for document release in another booth or section of the NSA outlet.

It became apparent that while queuing time was shortened to 30 minutes for application and payment procedures, the whole process of securing or finally receiving registry documents takes about two-three hours, or half of a working day.

There was observed greater convenience and satisfaction in the Pasay City outlet owing to more modern, spacious and air-conditioned facilities. The whole NSA building was divided 
into two portions, the processing section in the front side of the edifice and the release section at back of the edifice.Chairs were provided for waiting in addition to a television set to ease hours of waiting time.

On social variable

Observation and interview evoked the need to improve the congenial atmosphere in the NSA outlets.NSA staff and security personnel were focused on order and discipline, rather than the need to demonstrate caring and friendly service to clients. There were none or only a few smiling security and staff members in the processing stages. While security personnel wore uniforms, NSA staffers were not uniformed and wore casual attire. In the crowded East Avenue Main Outlet which received tens of thousands clients in a day, the atmosphere was tense, as there can be jostling in the queues.

Clients were mainly from the working and middle and lower-middle economic bracket of society. This createda market-like atmosphere in the NSA outlets, especially in the Main East Avenue Main Outlet.

In the Caloocan outlet, there was observed the presence of fixers who offered facilitation of document issuance in exchange for a fee. Observably, there was connivance with NSA office computer processing staff, as applicants who paid fixers were allowed to enter inside the computer section office to secure their documents.

On physical environment

The East Avenue Main Outlet delivered services under a large covered court site, which can be hot during the day or cold and windy during heavy rains. The Main outlet has closed beginning September 2016 as construction of a more spacious and modern edifice has commenced and to be completed in three years' time. In the meantime, frontline service in the main outlet has been transferred to Solicarel Building I and II in Sta. Mesa Manila While computer-supported procedures are in place in the new outlet, lack of space in the Solicarel Building creates the problem of congestion in NSA operations.

Metro Manila subsidiary outlets are open to serve residents of the NCR and nearby provinces. This point to the need forNSAservices in other parts of the country.

Presently, online communication has enabled the NSA to receive registry documents from abroad, e.g. U.S., Japan, European cities, etc. Online registry services can therefore be explored so that Filipinos here and abroad can secure needed registry documents without having to course their request through relatives in the NCR.

In summary, the study validated satisfactory consumer index for NSA's registry services in outlets in the National Capital Region. The single variable of shortened queuing time served as the basis for determining satisfaction index among consumers. Ocular visit and interviews confirmed satisfactory consumer index, with some apprehensions. Apart from 2-3 hours process, there is grave evidence of service fixing in NSA's Caloocan outlet. The prospects for further improvement surfaced through the use of more variables (technical, social and physical) for determining total consumer satisfaction on services. Computer online transmission can pave the way for online transactions to serve applicants abroad, as well as those in far-flung provinces of the country.

\section{Conclusion}

This study confirmed the satisfactory and efficient service NSA operations in the NCR with the following specific conclusions. The NCR consumer satisfaction surveys adopt a 
single variable consumer satisfaction construct in its survey. Total consumer satisfaction is yet to be determined through varied variable in survey. NSA staff and security personnel need orientation of social communication for friendly services to clients. There are not enough safeguards to secure the integrity of registry service. A fully computerized registry operation is yet to be planned and implemented to be aligned with a technological society in a borderless world.

\section{Acknowledgments}

The authors would like to acknowledge the participants and unconditional support from the Lyceum of the Philippines University.

\section{References}

[1] Karim, R.and Chowdhury, T. 2014. Customer Satisfaction on Service Quality in Private Commercial Banking Sector in Bangladesh. British Journal of Marketing Studies. 2. 1-11.

[2] Suchánek, P.andKrálová, M. 2018. Customer satisfaction and different evaluation of it by companies.Economic Research-EkonomskaIstraživanja. 31, 1, 1330-1350.

[3] Ray, J. 2018. Customer Satisfaction: A Comparative Study of Public and Private Sector Banks in Bangladesh. IOSR Journal of Business and Management (IOSR-JBM). 20, 1, 15-21.

[4] Mittal, A.and Srivastav, G. 2016. Impact of service quality on customer satisfaction in private and public sector banks. International Journal of Bank Marketing. 34. 606-622.

[5] Hennayake, Y. 2017. Impact of Service Quality on Customer Satisfaction of Public Sector Commercial Banks: A Study on Rural Economic Context. International Journal of Scientific \& Research Publications. 07. 156.

[6] Advantages \& Disadvantages of Computerized Systems. [Internet]. techwalla.com[cited 22 March 2020]. Available from:https://www.techwalla.com/articles/advantages-disadvantages-ofcomputerized-systems

[7] Shane, D. Chapter 1 Accounting Information Systems: An Overview Suggested Answers to Discussion Questions. [Internet]. [cited 22 March 2020]. Available from:https://www.academia.edu/23733910/CHAPTER_1_ACCOUNTING_INFORMATION_SYS TEMS_AN_OVERVIEW_SUGGESTED_ANSWERS_TO_DISCUSSION_QUESTIONS

[8] National Death Index. 2017. [Internet]. Centers for Disease Control and Prevention. [cited 22 March 2020]. Available from:https://www.cdc.gov/nchs/ndi/index.htm

[9] Cabildo III, A. 2012. Effectiveness of Semi-Automated Tax Mapping System at Quezon City Assessor's Office: Basis for Adaption of a Fully-Automated System. Lyceum of the Philippines Graduate School Journal. 71-83.

[10] Hussain, A., Mkpojiogu, E.O.C., Yusof, M.M. (2016). Perceived usefulness, perceived ease of use, and perceived enjoyment as drivers for the user acceptance of interactive mobile maps. AIP Conference Proceedings, 1761, art. no. 020051.

[11] Republic of the Philippines, Philippine Statistics Authority, Davao Oriental. [Internet]. [cited 22 March 2020]. Available from:https://psadavaoor.wixsite.com/psadavaoor/about-us 